\title{
Consumptive hypothyroidism in an Egyptian baby with benign neonatal hemangiomatosis: a case report
}

\author{
Kotb Abbass Metwalley ${ }^{*}$ and Hekma Saad Farghaly
}

\begin{abstract}
Introduction: Benign neonatal hemangiomatosis is a condition in which multiple cutaneous hemangiomas appear at birth or shortly thereafter; visceral complications are absent. Here, we report a case of a consumption hypothyroidism in an Egyptian baby with benign neonatal hemangiomatosis.

Case presentation: An 8-month-old Egyptian boy with benign neonatal hemangiomatosis was referred to our institution for evaluation of developmental delay. Initial examination revealed a quiet baby who was able to sit only with support. He had hypotonia, a large anterior fontanelle, puffy eyes, cold extremities, hypothermia, bradycardia, and abdominal distension. An examination of his skin revealed more than 100 dome-shaped red-purple cutaneous hemangiomas that varied in size from 5 to $10 \mathrm{~mm}$ on the back, the abdomen and the extremities without mucus membrane involvement. He had low serum free thyroxine concentration and triiodothyronine levels and high thyroid-stimulating hormone and reverse-triiodothyronine levels. A work-up that involved appropriate imaging ruled out visceral involvement. Based on the above mentioned data, a diagnosis of consumptive hypothyroidism due to benign neonatal hemangiomatosis was made. He was started on oral thyroid medication which was gradually increased to $90 \mu \mathrm{g}$ L-thyroxine daily $(15 \mu \mathrm{g} / \mathrm{kg} / \mathrm{day})$. After three months of treatment, he was able to sit alone without support and he had normal levels of thyroid-stimulating hormone and serum free thyroxine.

Conclusion: Thyroid function should be assessed periodically in babies with benign neonatal hemangiomatosis, especially if symptoms of hypothyroidism appear or the size and number of hemangiomatosis increase rapidly. Moreover, high doses of L-thyroxine may be needed to achieve euthyroidism during the infancy.
\end{abstract}

\section{Introduction}

Benign neonatal hemangiomatosis $(\mathrm{BNH})$ is a rare, selflimited disease where multiple capillary hemangiomas occur exclusively in the skin. Spontaneous regression occurs usually within the first two years of life [1]. BNH must be distinguished from diffuse neonatal hemangiomatosis $(\mathrm{DNH})$, a severe condition with a similar cutaneous presentation but with the presence of lifethreatening visceral hemangiomas [2]. Consumption hypothyroidism develops when the rate of inactivation of thyroid hormones surpasses the rate of their production and was described in association with $\mathrm{DNH}$ in children [3]. Reviewing the literature revealed that hypothyroidism in association with $\mathrm{BNH}$ has been reported

\footnotetext{
* Correspondence: kotb72@yahoo.com

Pediatric Endocrinology Unit, Department of Pediatrics, Faculty of Medicine, Assiut University, Assiut, Egypt
}

in only one case [4]. Here, we report a case of a consumption hypothyroidism in an Egyptian baby with BNH.

\section{Case presentation}

An 8-month-old Egyptian boy with BNH was referred to our institution from the Dermatology department for evaluation of poor activity and developmental delay. He was the second child of consanguineous parents; he was delivered at term by Caesarean section following an uncomplicated pregnancy and cried immediately after delivery with a birth weight of $3.5 \mathrm{~kg}$. There was no family history of hemangiomas or congenital malformation. Neonatal screening tests were normal. His mother observed the appearance of multiple pinpoint erythematous lesions all over his body at the age of 35 days that increased rapidly in number and size. She reported that her baby remained well until the age of three months. 
At the age of six months, he was unable to roll over prone to supine or vice versa. An examination revealed a quiet baby who was able to sit only with support but unable to orient to voice. His height and weight were $25^{\text {th }}$ percentile. Vital signs on admission were recorded as follows: temperature, $36^{\circ} \mathrm{C}$; blood pressure, $80 / 60 \mathrm{mmHg}$; and heart rate, regular at 66 beats/minute. A physical examination found generalized hypotonia, a wide anterior fontanelle, puffy eyes, cold extremities, and mild abdominal distension. There were no signs of rickets or thyroid enlargement. An examination of his skin revealed more than 100 dome-shaped red-purple cutaneous hemangiomas that varied in size from 5 to $10 \mathrm{~mm}$ on the back, the abdomen and the extremities with no mucus membranes involvement (Figure 1). Other systematic examinations were unremarkable. Thyroid ultrasonography and scan, ophthalmic examination, laryngoscopy, bone screening and computed tomography (CT) scan of the brain were normal. Repeated chest radiography, echocardiography, and abdominal ultrasonography with a Doppler study were normal which ruled out respiratory system, cardiovascular and hepatic involvement. Laboratory studies revealed that serum electrolytes, hemogram, blood glucose and aminotransferase levels were normal. A hormonal assay revealed a serum thyroid-stimulating hormone (TSH) of $176 \mu \mathrm{IU} / \mathrm{mL}$ (normal 0.3 to $5.0 \mu \mathrm{IU} / \mathrm{mL}$ ), serum free thyroxine (FT4) of $0.4 \mathrm{ng} / \mathrm{dL}$ (normal 1.0 to $2.5 \mathrm{ng} / \mathrm{dL}$ ), and serum triiodothyronine (T3) of $65 \mathrm{ng} / \mathrm{dL}$ (normal 85 to $250 \mathrm{ng} / \mathrm{dL}$ ). Serum reverse-T3 (rT3) level was $865 \mathrm{ng} / \mathrm{dL}$ (normal 10 to $50 \mathrm{ng} / \mathrm{dL}$ ). The mother's thyroid function tests were normal and no thyroid autoantibodies were found in the mother or in the baby. Based on these findings, a diagnosis of consumptive hypothyroidism due to $\mathrm{BNH}$ was made. He was started on oral thyroid

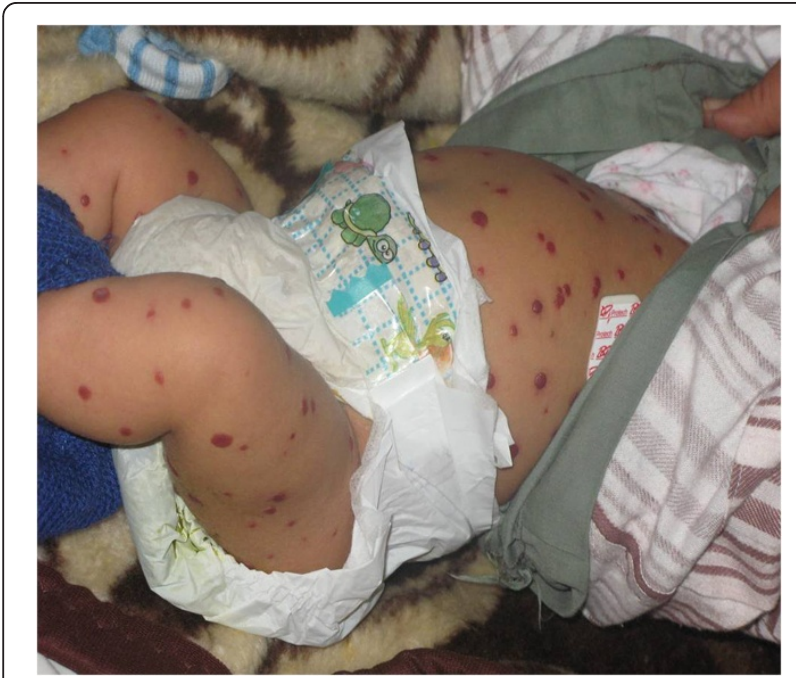

Figure 1 An Egyptian baby with hypothyroidism associated with benign neonatal hemangiomatosis. medication which was gradually increased to $90 \mu \mathrm{g} \mathrm{L}-$ thyroxine daily $(15 \mu \mathrm{g} / \mathrm{kg} /$ day $)$. After one month of treatment, blood hormone levels were: TSH $45 \mathrm{mIU} / \mathrm{mL}$, FT4 0.99ng/dL, T3 80ng/dL and rT3 70ng/dL. Blood hormone levels were completely normal two months later (TSH $1.99 \mathrm{mIU} / \mathrm{mL}$, FT4 $1.44 \mathrm{ng} / \mathrm{dL}$ and T3 $40.23 \mathrm{ng} / \mathrm{dL}$ ) with spontaneous involution of some of his cutaneous hemangiomas. He was able to sit without support at that time. $\mathrm{He}$ is still seen at three-month intervals for out-patient follow-up visits.

\section{Discussion}

Hemangiomas are benign vascular neoplasms, present in nearly 1 to $2 \%$ of newborns and 10 to $12 \%$ of babies by one year of age. The hemangiomas may occur anywhere on the skin but the head and neck are the most commonly affected sites, followed by the trunk and limbs. In approximately 10 to $20 \%$ of babies with hemangiomas, the lesions are multiple [5]. Although the exact mechanism for hemangioma development remains unknown, vascular growth factors seem to play a role in the pathogenesis. Proliferation most probably results from an imbalance between positive and negative angiogenic factors expressed by the hemangioma and adjacent normal tissue [6]. BNH is a nonheritable disorder in which multiple cutaneous capillary hemangiomas appear in an eruptive manner during the neonatal period [7]. BNH was first reported by Stern et al. [8]. They increase rapidly in number and size (reaching up to $2 \mathrm{~cm}$ in diameter) during the first few months and follow a benign course with spontaneous regression, usually within the first four months after their appearance. In general, visceral involvement is absent or unremarkable. Histologically, lesions are typical capillary hemangiomas. Treatment is usually not required because spontaneous resolution occurs with excellent cosmetic appearance [1].

Because benign and diffuse neonatal hemangiomatosis probably exist along a continuum, babies younger than three months with numerous, small cutaneous hemangiomas should be carefully monitored. In this group of patients, in addition to a work-up directed by history, physical examination, general chemistry and blood counts, screening abdominal ultrasonography with Doppler studies may be considered to rule out hepatic involvement [9].

It is well known that thyroid hormones are necessary for growth and development during early infancy and that the early detection and treatment of hypothyroidism is important to prevent growth retardation and intellectual loss [10]. In the first year of life, approximately three to five intelligence quotient (IQ) points are lost for each month in which hypothyroidism remains untreated. This developmentally critical period corresponds to the proliferative phase of hemangiomas and arouses concern 
that babies with this tumor may be at risk for permanent neurologic damage. Infantile hypothyroidism is often occult, and even severe symptoms could be masked by complications of the hemangioma itself [11].

The aim of treatment of consumptive hypothyroidism due to $\mathrm{BNH}$ is to maintain a normal thyroxine level which is vital for the developing brain especially during infancy. This can be achieved by monthly checking of the thyroid function especially during the rapid phase of hemangioma growth then every two months during the stationary and resolution phases [1].

Consumptive hypothyroidism develops when the rate of inactivation of thyroid hormones surpasses the rate of their production, and this may be attributed to the presence of a high level of 3 iodothyronine deiodinase in the hemangioma tissue which catalyzes the conversion of $\mathrm{T} 4$ to rT3 and of T3 to diiodothyronine, both of which are biologically inactive [3].

Our index case was diagnosed to have consumptive hypothyroidism secondary to $\mathrm{BNH}$ which manifested by developmental delay, puffy eyes, wide anterior fontanelles, cold extremities, hypothermia, bradycardia, abdominal distension, high TSH and rT3 levels, and low FT4 and T3 [12]. Hypothyroidism due to BNH could not be detected on newborn screening as the lesions appeared around the 5th week of life.

The clinical features of both consumptive hypothyroidism due to $\mathrm{BNH}$ and simple congenital hypothyroidism are similar, and even some laboratory data are shared by both diseases, for example high TSH and low FT4 and T3 levels. The negative neonatal screening test, late onset of symptoms, normal thyroid scan, presence of multiple skin hemangiomas, high rT3 and the need of a high dose of Lthyroxine treatment are in favor of the diagnosis of consumptive hypothyroidism due to BNH. L-thyroxine in a dose of 5 to $10 \mu \mathrm{g} / \mathrm{kg} /$ day is generally adequate for treating congenital hypothyroidism, whereas our index case required higher replacement doses of L-thyroxine $(15 \mu \mathrm{g} / \mathrm{kg} /$ day $)$ to reduce serum thyrotropin concentrations to normal which are thought to reflect tumor size and type 3 deiodinase activity [3].

\section{Conclusion}

Thyroid function should be assessed periodically in a baby with $\mathrm{BNH}$, especially if symptoms of hypothyroidism appear or the size and number of hemangiomatosis increase rapidly. Moreover, high doses of L-thyroxine may be needed to achieve euthyroidism during the infancy.

\section{Consent}

Written informed consent was obtained from the patient's parents for publication of this case report and any accompanying images. A copy of the written consent is available for review by the Editor-in-Chief of this journal.

\section{Abbreviations}

BNH: Benign neonatal hemangiomatosis; CT: Computed tomography; DNH: Diffuse neonatal hemangiomatosis; FT4: Serum free thyroxine; rT3: Reverse-T3; T3: Triiodothyronine; TSH: Thyroid-stimulating hormone.

\section{Competing interests}

The authors declare that they have no competing interests.

\section{Authors' contributions}

KA and HS diagnosed, investigated, followed up, managed the patient and drafted the manuscript. Both authors read and approved the final manuscript.

Received: 9 July 2012 Accepted: 6 November 2012

Published: 18 February 2013

\section{References}

1. Leung A, Rafaat M: Benign neonatal hemangiomatosis. Pediatr Dermatol 2003, 20(2):161-163

2. Held $J$, Haber RS, Silvers DN, Grossman ME: Benign neonatal hemangiomatosis: review and description of a patient with unusually persistent lesions. Pediatr Dermatol 1990, 7(1):63-66.

3. Vergine G, Marsciani A, Pedini A, Brocchi S, Marsciani M, Desiderio E, Bertelli $\mathrm{S}$, Vecchi V: Efficacy of propranolol treatment in thyroid dysfunction associated with severe infantile hepatic hemangioma. Horm Res Paediatr 2012, 78(4):256-260.

4. Dyall-Smith D, Cowen P: Benign neonatal hemangiomatosis. Int J Dermatol 1992, 31:336-338.

5. Drolet BA, Esterly NB, Frieden IJ: Hemangiomas in children. N Engl J Med 1999, 341:173-181.

6. Lembo S, Balato A, Raimondo A, Donofrio P, Lembo C, Balato N: A preterm infant with benign neonatal hemangiomatosis and persistent patent ductusarteriosus: a curious comorbidity. Giornaleltaliano di Dermatologia e Venereologia 2012, 147(3):321-324.

7. Messaritakis J, Anagnostakis D, Feingold M: Benign neonatal hemangiomatosis (picture of the month). Am J Dis Child 1986, 140:447-448.

8. Stern JK, Wolf JE, Jarratt M: Benign neonatal hemangiomatosis. J Am Acad Dermatol 1981, 4:442-445.

9. Stanley P, Geer GD, Miller JH, Gilsanz V, Landing BH, Boechat IM: Infantile hepatic hemangiomas: clinical features, radiologic investigations, and treatment of 20 patients. Cancer 1989, 64:936-949.

10. Mandel SJ, Brent GA, Larsen PR: Levothyroxine therapy in patients with thyroid disease. Ann Intern Med 1993, 119:492-502.

11. Huang SA, Tu HM, Harney JW, Venihaki M, Butte AJ, Kozakewich HP, Fisman SJ, Larsen PR: Severe hypothyroidism caused by type 3 iodothyronine deiodinase in infantile hemangiomas. N Engl J Med 2000, 343:185-189.

12. LaFranchi S: Congenital hypothyroidism: etiologies, diagnosis, and management. Thyroid 1999, 9:735-740.

doi:10.1186/1752-1947-7-48

Cite this article as: Metwalley and Farghaly: Consumptive hypothyroidism in an Egyptian baby with benign neonatal hemangiomatosis: a case report. Journal of Medical Case Reports 2013 $7: 48$

\section{Submit your next manuscript to BioMed Central and take full advantage of:}

- Convenient online submission

- Thorough peer review

- No space constraints or color figure charges

- Immediate publication on acceptance

- Inclusion in PubMed, CAS, Scopus and Google Scholar

- Research which is freely available for redistribution 